\title{
Using small futorial groups within a blended Bachelor of Midwifery programme: Bridging the theory-practice divide
}

\author{
Mary Kensington ${ }^{A, B} M P H, B A$, DipTchg (Tertiary), ADM, RGON, RM - Lorna Davies ${ }^{B} M A, B S C$ (Hons), \\ PGCEA, RM, RN・ Rea Daellenbach ${ }^{B}$ PhD, BA (Hons) - Ruth Deery ${ }^{C}$ PhD, BSC (Hons), ADM, RM, \\ RGN• Julie Richards ${ }^{B}$ MMid, DTLT, RM, RN
}

${ }^{\mathrm{A}}$ Corresponding

Author: mary.

kensington@ara.ac.nz

${ }^{B}$ Ara Institute of

Canterbury

${ }^{\mathrm{C}}$ University of the West of Scotland

\begin{abstract}
Background: In 2009 an innovative Bachelor of Midwifery programme was introduced using a blended delivery model to enable students to study and gain practice experience within their own communities. Students learn much of the theoretical content from their homes through access to online resources and virtual classrooms. In recognition for the potential of social isolation and to encourage cooperative learning between student and lecturer, a modified version of the Oxford Tutorial model was adopted. Students meet in small tutorial groups in their areas each week with a locally employed lecturer, and attend scheduled block study weeks on campus throughout the year.
\end{abstract}

Aim: To critically evaluate the introduction of this programme.

Method: A participatory action research methodology was used in which students' views were gathered through anonymous questionnaires and focus group interviews. Ethics approval was gained through Ara Human Research Ethics Committee. The particular focus of this article is the students' views in relation to the small group tutorials.

Findings: We found that small group tutorials are helpful in assisting students to manage feelings of isolation and the competing demands of home life and study. Students developed a community of inquiry which was pivotal to negotiating the gap between theory and clinical practice: what they are taught and what they see in midwifery settings.

Conclusion: The research found that the midwifery tutorial model is valued by all students and seen as the "hub" of the programme, effectively bridging the gap between theory and practice.

Keywords: midwifery education, blended learning, community of inquiry, Oxford Tutorial

\section{INTRODUCTION}

The rapid pace of technological innovation has meant the way in which students learn is changing, and pedagogical design and delivery need to reflect these demands (Skrypnyk et al., 2015). In the field of midwifery education, enabling students to flourish in increasingly diverse practice contexts requires creative, innovative and responsive pedagogical approaches.

In recent years, midwifery education in New Zealand (NZ) has been faced with the dual challenges of addressing workforce shortages, many of which were rurally based (Hendry, 2009), and the need to increase accessibility to programmes for students who reside in rural and regional areas. Until recently, midwifery education was campus based and students had to commit to attending classroom sessions, which determined that they had to reside in one of the five main cities that provided midwifery education. This was challenging for rural and regionally based women with families, who would often have little other option than to relocate their families in order to complete their midwifery education. This was costly for the families involved but, more significantly, could leave communities deprived of a rural midwife if the family did not return following completion of the midwifery programme.

An exponential growth in technological advances in online learning has offered an opportunity for tertiary education providers to explore other models of education. Tertiary institutions are looking increasingly towards blended learning as an alternative mode of education delivery. Blended learning includes online learning, thereby offering choice and flexibility for students as an "any time, any place, anywhere" way of learning (Eggermont, Bloemendaal, $\&$ van Baalen, 2013). The added advantage of a blended model is that it also has face-to-face components as a way of ensuring social interaction and discussion (Skrypnyk et al., 2015). In this article, we describe an innovative model of blended learning introduced at a tertiary institution to accommodate students living in remote areas. The article begins with a background on what prompted the change in delivery and then provides a literature review on blended learning. The research is explained and the findings are presented.

\section{BACKGROUND}

In 2007 the Midwifery Council of New Zealand (MCNZ) preregistration education standards were amended to lengthen the academic year and included a requirement to improve accessibility for students in rural and provincial locations (MCNZ, 2007). This created an opportunity for the two Schools of Midwifery in the South Island of NZ to collaboratively redesign the undergraduate midwifery degree programme. Both institutions agreed that facilitating students to study midwifery in their home area would potentially increase the number of midwives who would choose to practise in their local communities. 
The programme was launched in 2009 after extensive planning and design by both Ara Institute of Canterbury (Ara, formerly Christchurch Polytechnic Institute of Technology, CPIT) in Christchurch and Otago Polytechnic (OP) in Dunedin. A blended learning model was agreed and adopted for the joint programme in order to support the concept of a "satellite delivery" (Figure 1).

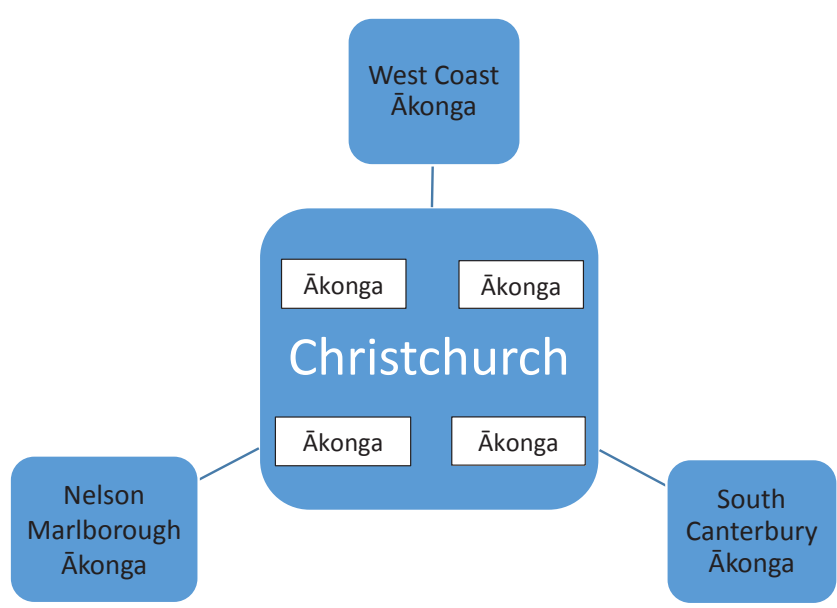

Figure 1. Representation of the range of satellite/tutorial (ākonga) groups at Ara Institute of Canterbury (not including Otago Polytechnic and its satellites)

The model enables students to access the programme both centrally at Ara (Christchurch) or OP (Dunedin), as well as at a number of other satellite sites. When the programme commenced in 2009, Ara introduced its first satellite in the north of the South Island in Nelson/Marlborough, and this was followed by South Canterbury and the West Coast in 2010. Otago Polytechnic began with satellites in the lower South Island and later extended delivery to the lower North Island (Patterson, Baddock, Pairman, Griffiths, \& Miller, 2015).

Students now spend much of the programme based in their own geographical areas and, in the interests of parity, the satellite model within a blended learning approach was adopted for all areas in which the programme is available. This ensures all students have a similar experience regardless of where they are situated.
The degree is four years of study ( 480 credits) but is delivered over three calendar years, with each year providing 45 weeks of study in keeping with the MCNZ requirements. Students complete 4800 total hours, of which 2400 is midwifery practice experience. They gain experience across the midwifery scope of practice in antenatal, labour/birth and postnatal settings, working with both community caseloading midwives and hospital-based midwives in a range of primary, secondary and tertiary settings.

The programme uses a combination of learning methods to enable students to study within their own homes and communities (Figure 2). Each component was chosen to best suit the purpose of the learning with consideration of how learning in each method could be integrated with the other components (Littlejohn \& Pegler, 2007).

Students learn much of the theoretical content from home, accessing the online resources/modules and virtual classrooms. The potential for social isolation identified in the literature and the need for cooperative learning between student and teacher led us to design a modified version of the Oxford Tutorial model (Ashwin, 2005; Palfreyman, 2008). The Oxford model is based on small groups of students (three to five) meeting weekly with a tutor to discuss and debate topics related to their study. This has been used effectively with undergraduate students in different settings for centuries (Mills \& Alexander, 2013) and is seen as a pedagogical approach that creates learning and assessment opportunities, as well as catering for the individual learning needs of students (Palfreyman, 2008).

In the first two years of the programme, the students are placed in ākonga of four to eight students. (Ākonga is a Māori word for seed, nurturing and cooperative learning and has been used to denote a group of learners.) The groups are geographically based either on central campus or in rural satellite settings. Ākonga meet weekly, face-to-face and are facilitated by a locally employed lecturer known as a kaiako (facilitator of learning). The kaiako leads debriefing and discussion of practice experiences; teaches practice and communication skills; and ensures alignment with course outcomes. Third year students are assigned a kaiako and they maintain regular contact through a mix of phone, face-toface and online contact throughout the year, although now on a

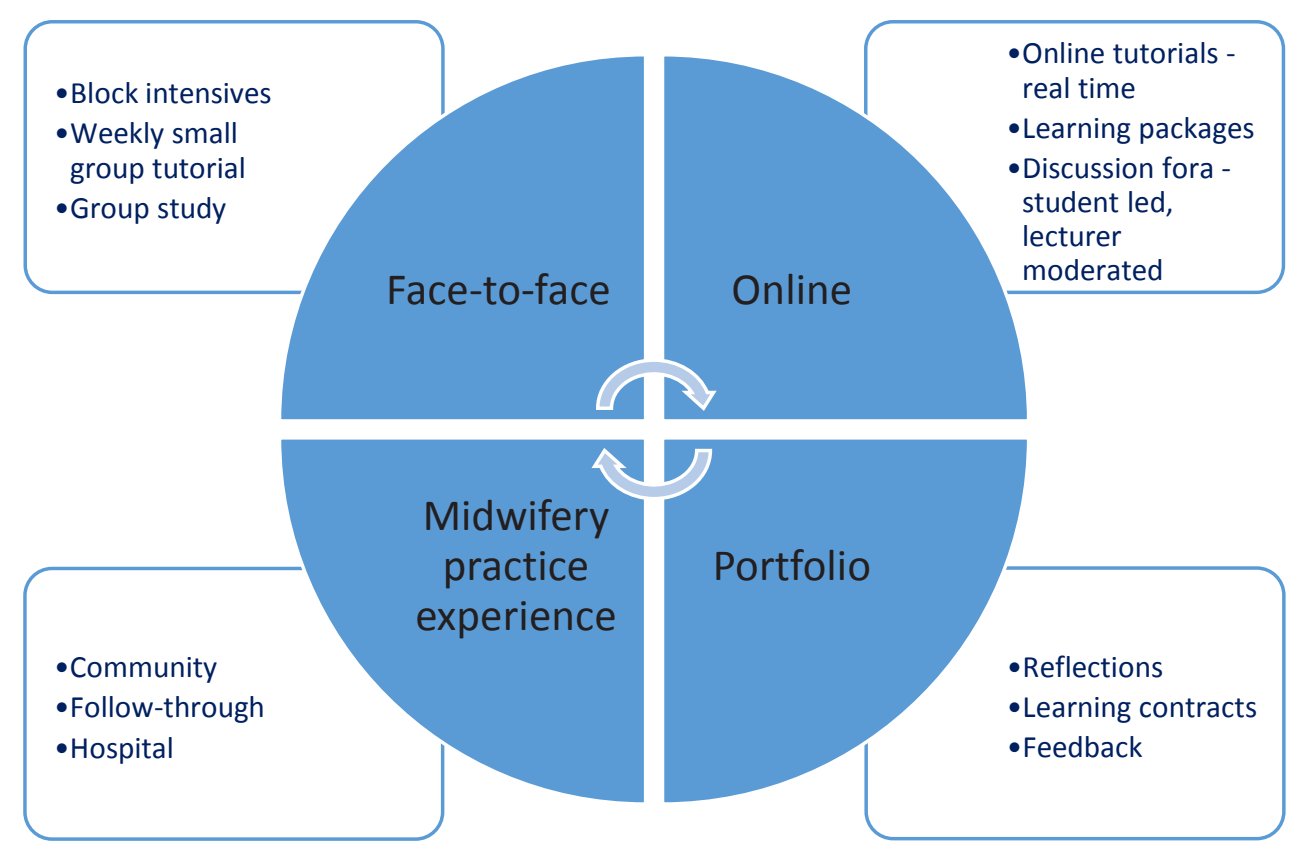

Figure 2. Blended learning model for Bachelor of Midwifery 
one-to-one basis. Ara students additionally attend intensive block weeks of study in Christchurch each year. These weeks provide practical sessions and theoretical content that is better suited to larger group delivery. They also offer an important opportunity for students to engage with a larger cohort of other students in order to socialise and share their experiences.

\section{LITERATURE REVIEW}

Technology has been increasingly used to enhance course content and delivery. Research supports the merging of an online and face-to-face blend of learning (Skrypnyk et al., 2015). Blended curricula have been used in health education and clinical settings internationally. Much of the research on blended learning in health relates to students' experiences of either undertaking a component of their undergraduate study as blended learning (Sidebotham, Jomeen, \& Gamble, 2014) or completing postgraduate study (Glogowska, Young, Lockyer, \& Moule, 2011). However, one study (Milne, Skinner, \& Baird, 2014) surveyed first- and secondyear undergraduate students at another NZ midwifery school which offers a blended curriculum that includes face-to-face, online modules and lectures delivered via video conferencing. Students in this research reported difficulties with using the technology and rated their engagement with the programme higher through the face-to-face sessions than through video-conferencing.

\section{Technology has been increasingly used to enhance course content and delivery. Research supports the merging of an online and face- to-face blend of learning.}

Several studies have found that the development of a community of inquiry is key to sustaining blended learning and that frequency of interaction enhances this outcome (Garrison \& Kanuka, 2004; Glogowska et al., 2011). Garrison and Kanuka (2004, p.97) stress that a "sense of community and belonging must be on a cognitive and social level if the goal of achieving higher levels of learning is to be sustained". The authors emphasise the importance of a teaching presence within blended learning to manage the environment and to help focus and facilitate student learning experiences. They also maintain that where there is a cohesive community of inquiry then blended learning is able to support "higher levels of learning through critical discourse and reflective thinking" (Garrison \& Kanuka, 2004, p.98). Studies overall report that blended learning is enjoyable, supportive and motivating for learners (Güzer \& Caner, 2014), offering students and lecturers greater flexibility and accessibility without compromising the face-to-face contact (Skrypnyk et al., 2015). Research also suggests that students are compelled to read, speak, listen and think, which shifts them from a passive to an active learner (Kaur, 2013).

Although many studies demonstrate the importance of including face-to-face sessions within a blended programme, the amount and type of face-to-face required for blended delivery are not so evident (Garrison \& Kanuka, 2004; Glogowska et al., 2011; Milne et al., 2014). Face-to-face is often referred to in relation to classroom teaching, whilst "tutorial" relates to online provision. No studies were found that referred to small group face-toface tutorials as a significant component of blended learning programmes. Whilst the Oxford Tutorial model is not usually linked with blended learning, the success of these small groups in supporting students to take an active role in their learning was of interest to us (Palfreyman, 2008). Interestingly, Trigwell and Ashwin's (2003) study found that students who considered the tutorials an opportunity for their ideas to be critically examined were more likely to feel supported in their learning than students who saw the tutorials as a teacher-centred learning environment.

\section{METHODOLOGY}

In 2010, following the introduction of the new Bachelor of Midwifery, the midwifery teaching team at Ara commenced a participatory action research (PAR) (Kindon, Pain, \& Kesby, 2007; Reason \& Bradbury, 2006) project titled "Learning Midwifery in a Blended Teaching Environment". PAR as a methodology is variously described as an approach to social investigation, an educational process and a means of taking action to deal with a problem (Kindon et al., 2007; Koch \& Kralik, 2009). The project employed a cyclical PAR approach based on reiterations of three phases: collect, analyse and act. This involved collecting, analysing and evaluating data and then implementing actions in relation to the themes identified. This was followed by further rounds of collection, analysis and action. Koch and Kralik (2009) note that "[p]articipatory action research often appeals to clinicians and others working in practice environments because it translates quickly into action so that change can be observed during the process of research" (p.24). In its purest form, it is a methodology that is initiated and driven by all the participants (Baum, MacDougall, \& Smith, 2006) but in this study the research process was primarily driven by the researchers within the teaching team. However, Schneider (2010) developed a continuum within the context of PAR that spans from advisory through to consultation, collaboration and finally control. This study comes under the consultation classification described as recognition that the participants have knowledge that may be valuable, but the primary researcher retains control of the project.

During the design of the research project, consultation was undertaken with Māori through the Kaiarahi of Ara who approved this project. Ethics approval was gained from the Ara Human Research Ethics Committee (No. 1290, granted 27 ${ }^{\text {th }}$ May, 2010).

\section{Research Questions}

The research questions were:

1. What do students and educators identify as the strengths and weaknesses of the new blended delivery curriculum?

2. What are the barriers and challenges for students and educators in the blended delivery model and which factors have proved to be of assistance?

3. Does the programme promote an integrative approach to midwifery theory and practice?

4. In what ways does the blended programme enable new graduates to feel competent and confident to practise as midwives?

\section{METHOD}

Data were collected from cohorts of approximately 30 students in each year from 2010 to 2014. The students were invited to participate during their second year of the programme and in their first year as a graduate midwife. Students were either invited to complete written questionnaires with open-ended questions or, in alternate years, participate in a focus group. All data collection was anonymised so that the teaching team did not know which students took part. The response rates from the questionnaires ranged from $43 \%$ to $80 \%$. There were three rounds of focus groups and about 
one third of the students from each cohort participated. The focus groups were facilitated by a visiting midwifery scholar from the United Kingdom (UK) in order to avoid any potential conflict of interest with staff conducting research on current students and to encourage open and transparent responses from the students. All identifying information about individual students was removed from the transcripts before being analysed by the teaching team.

The students were invited to evaluate all blended components of the programme but the focus of this article is on the first three research questions that relate to the student experiences of the tutorial model.

The data were analysed each year and an iterative "interpretive description” approach (Thorne, Reimer Kirkham, \& O’FlynnMagee, 2004) was used by the teaching team. Interpretive description is a method used in qualitative research that employs a constructivist approach to inquiry. The aim of the method is to generate knowledge that is relevant for practice-based contexts.

The interpretation of the data was discussed with students to gain their perspectives on the analysis. In keeping with the methodology, the teaching team developed strategies to address those aspects of the blended model that students found challenging, as well as to strengthen aspects that students identified as enhancing their learning. Subsequent rounds of the action research cycle have enabled the research team to reflect critically on the effectiveness of these changes for students.

\section{Demographics}

Demographic data about the participants were not collected in order to ensure that the researchers could not identify individual students. The demographic profile of all students enrolled in the programme was that they were women with a range of ages from 18 to 50. Approximately two-thirds had dependent children and one third lived in rural areas. Between $10 \%$ and $20 \%$ in each cohort were Māori and approximately 10\% were from other nonEuropean New Zealand ethnic backgrounds.

\section{FINDINGS}

One of the questions in the second-year and graduate midwife questionnaires asked participants to reflect on their key learning experiences from the ākonga. They were also asked to comment on any other benefits or challenges for learning within these groups. Aspects were further explored within the focus groups.

\section{Themes}

A number of themes were elicited from the data analysis. These were: social connection and isolation; communities of inquiry; challenges of the tutorial system; and integrating theory and practice. There was consistency in the themes across all cohorts who participated in the project.

\section{Social connection and isolation}

Students valued the flexibility of the online aspects of the programme, although many commented on feelings of "isolation" when they were working through the online course materials. The words of the following students capture their views.

VERY isolating. Lack of discussion. Unsure if on the right track, or spending the right amount of time doing certain things. (Year 2, 2010)

I think one of the down points for me ... is there's no one sat next to you to bounce ideas off or just to ask one of those silly little questions you want to just to clarify. I think you

\section{... there's nobody in your room; you're just in your room with you. (Year 2, 2011)}

The quotes seem to suggest that not being based in the classroom could lead to student isolation. They also highlight the possibility that students were not engaging with, or fully understanding, the online materials, which could have added to their feelings of isolation.

The following quotes illustrate how the weekly ākonga helped to break down these feelings of isolation and provide opportunity for social connection.
... it is nice to see other people from the class as working at home from the computer can feel quite isolating at times. (Year 2, 2010) ... closeness of the groups and feeling that you are not alone
in your study. (Year 2, 2010)

Students placed value on the ākonga as a safe haven to share experiences and provide support when life was demanding. For example:
The akonga [sic] tutorial group has provided a safe place to share experiences... (Year 2, 2012)

As such, I have found that we students bond well with each other and this in turn provides an often much needed support network when times become challenging. (Year 2, 2012)

... [äkonga] group especially in year 1 \& 2 were absolutely
vital for me... great learning to listen to others [sic]
experiences, and also to talk about mine. (New graduate,
2012)

The comments indicate that the àkonga provided opportunity for support and debriefing, which mitigated feelings of isolation as well as enabling students to manage competing demands of home and study.

\section{Communities of inquiry}

Some of the students commented on the positive value of the intensive blocks; however, all participants commented on the importance of the weekly àkonga and there was recognition that the group created an important learning space. The students were enabled to develop critical reflective and questioning skills within the ākonga.

The tutor also expands our thinking by questioning what we have seen in practice and reflecting on our experiences is great! (Year 2, 2010)

The students valued the significant role that their colleagues played in creating a community of inquiry.

\section{Sharing of follow-through experiences and being able to learn from the experience of classmates $\rightarrow$ vicarious exposure to a whole variety of experiences in clinical and community settings. (Year 2, 2010)}

\section{I think too that we also learn perhaps without realising we are learning to be with women ... because we are diverse people sharing different opinions and you do have to - well I learnt like greater tolerance and understanding. (Year 2, 2011)}

The quotes suggest that students appreciate that the group is not solely about learning skills and reflecting on practice but is also 
facilitating self-reflection and, in particular, highlighting how they communicate and interact with others. The students realise these skills will support them when working in the wider midwifery community.

\section{Challenges of the tutorial system}

Some of the students commented on the difficulty of getting to the àkonga and the consequences of missing them. Some challenges around missing sessions were:

\section{The only challenge about learning within the akonga [sic] group is that sometimes it is missed due to clashing with clinical placements. ... If 1 or 2 are missed in a row it is easy to feel disconnected or isolated from each other. (Year 2, 2012)}

In year two the practical requirements of attending a woman's antenatal, labour/birth and postnatal care as well as attending as many of the ākonga as possible affected a small number of students.

The students were aware that the make-up of each àkonga group created a unique group identity. However, this meant that for some they were anxious and felt they might be missing out when they heard different issues/topics were discussed in other groups.

\section{The experience is solely reliant on the tutor - most tutors have a 'focus' and therefore excel in that area, sometimes leaving other areas lacking - the tutors need to agree. (Year 2, 2012) \\ [äkonga] needs to have a practical underpinning, tutors that had a doll and pelvis with them ... were great, the ones that only discussed and focussed on the experience did not meet students learning needs. (Year 2, 2012)}

In year three of the programme it is not practical to continue the weekly àkonga as students are in placements throughout the country. New graduates noted the following in the online questionnaire.

\section{Thoroughly enjoyed my [äkonga] groups, was upset that we lost this connection in year 3 but understand this was not possible to do in that year. (New graduate, 2012) \\ Missed out face to face with lecturers and each other and sharing of knowledge. (New graduate, 2012)}

This change had a significant impact on the students and highlighted the value they placed on the àkonga in their first two years.

\section{Integrating theory and practice}

A significant finding of the research was the important role of the àkonga in providing the opportunity and assisting the students to integrate theory and practice.

\section{... looking at all the aspects involved in the different births the students experienced. Intertwined with this was the learning as to how to be a midwife - looking at ethics, and ways of practice. (Year 2, 2010)}

The value that they placed on their kaiako and their colleagues to help them negotiate their learning was clearly stated.

Really great to debrief and share experiences (both good \& bad), and ideas with other students. Very helpful to have a tutor to answer questions about andlor expand on ... what experienced/observed in practice. (Year 2, 2012)
The weekly contact with students \& tutor allows for rich discussion, the opportunity to ask questions and explore tricky concepts \& scenarios such as ethical issues or complex cases. I find I learn a great deal from a student sharing an experience and the tutor breaking it down in order to explore the finer points. The input from other students encourages me to look at the experience from different perspectives, challenging my own thoughts and ideas about issues. The small group works well for me as I feel it is a safe place to share - less intimidating than a large group. (Year 2, 2012)

The ākonga, by providing a space for students to debrief and learn from each other, with kaiako bringing their midwifery knowledge and spirit of inquiry, enabled the students to integrate theory and practice.

\section{DISCUSSION}

The questionnaire and focus group responses provided insight and understanding of the student experience within the àkonga. The thematic analysis identified that the students view the ākonga as serving as the axis of the blended delivery programme.

The question of how many students constitute the perfect group size has been widely debated and disputed in the literature for many years, with most educationalists agreeing that between five and eight is an optimal range (Booth, 1996; Exley \& Dennick, 2004; Mills \& Alexander, 2013). The group size needs to allow for the dialogue and collaboration that is integral to learning. A weekly three-hour, face-to-face small group tutorial was introduced for students in the first two years of the midwifery programme and the size varied from four to eight students, depending on location.

Palfreyman (2008) proposes that the Oxford Tutorial model is an effective strategy to adopt for undergraduate students because it is seen as the best way to stimulate students to learn the skills of research and critical analysis. Our modification of the tutorial model additionally demonstrates connection and the development of a community of practice, something that is not remarked on in the literature. The main precept of a community of practice is that participants share a domain of interest and, through their collective learning and interactions within this community, develop shared practice (Wenger-Trayner \& Wenger-Trayner, 2015). We found that students initially formed social connections within their ākonga (Mills \& Alexander, 2013). However, we also observed the development of a community of practice which is reflected in the students' comments. Through sharing personal narratives, as well as reflections on their practice experiences, students mutually support and learn from each other. This point is supported in the literature where studies have noted the importance of ensuring there are opportunities for students within blended learning to come together face-to-face (Glogowska et al., 2011; Kaur, 2013). The value of face-to-face time is reiterated in the findings, showing that the ākonga has the potential to reduce feelings of social isolation.

The ākonga not only provides support and social connection but also creates communities of inquiry (Garrison \& Kanuka, 2004). Interestingly, Garrison and Kanuka (2004) stress the importance of students having an awareness of community and belonging if they are to maintain higher levels of learning. This seems to be borne out with our students as it appeared that the àkonga, as well as creating opportunity for social interaction, were able to provide a positive and collaborative learning environment that led to the development of communities of inquiry and communities of practice. This is reflected in the quotes where students demonstrate 
interpersonal communication skills such as adaptability and sensitivity. In addition, they engage in critical inquiry through the debriefing of midwifery practice experience that can raise complex ethical dilemmas.

\section{[W]e found that the facilitative guidance of the kaiako encouraged the students to challenge each other, thereby stimulating reflective learning and critical analysis.}

The kaiako plays a key role in coordinating the development of these communities by managing the environment and providing support alongside the facilitation of student learning experiences (Garrison \& Kanuka, 2004). The role requires an advanced facilitation skillset on the part of the kaiako. The transmittal model, which indicates a move from being the "sage on the stage" to that of the "guide on the side" (King, 1993 p.30), has now been appended with the learner-centred conception of "curator of knowledge" (Siemens, 2008, p.17). Like the curator of cultural heritage, the kaiako needs to foster and encourage learner exploration without being too directive. However, whilst the students should be given the freedom and space to explore, the "key concepts of a discipline are transparently reflected through the curatorial actions of the teacher" (Siemens, 2008, p.17). In the àkonga this exploration is achieved primarily through facilitating the debriefing of the students' practice-related experience and encouraging storytelling in order to "unpack" the experience for reflection. Our research has also highlighted that, when several àkonga are running concurrently, it is important that the kaiako are collaborating in order to provide a degree of consistency. In line with a PAR framework, the researchers facilitated discussions with the teaching team to identify strategies to ensure there was more consistency and agreement between kaiako for each year group. A workshop was also organised to discuss and review the challenges of small group tutorials in light of the findings. The principles of flexibility, interaction, reflexivity and engagement were reiterated as key strengths of small group teaching (Mills \& Alexander, 2013). A key concern for us in designing the new curriculum was that it could widen the theory-practice gap already debated in the literature (Wilson, 2008). Theory-practice integration had always been a strong focus of our previous curriculum and we had some concerns that we might lose this in the new blended programme. Instead we found that the facilitative guidance of the kaiako encouraged the students to challenge each other, thereby stimulating reflective learning and critical analysis (Mills \& Alexander, 2013). Through this process students are changing their conceptions of knowledge through emerging views. A significant finding in this study was the recognition of knowledge as co-constructed between student/s and kaiako. This aspect is also described within the Oxford Tutorial model where the tutor acts as a constructive critic in order to cultivate the student's "critical spirit" (Palfreyman, 2008, p.18).

The findings also demonstrate that ākonga are pivotal in enabling students to learn to negotiate the gap between what they are taught and what they see in midwifery settings.

\section{STRENGTHS AND WEAKNESSES}

This research has explored the views of midwifery students across three cohorts of the undergraduate programme of one NZ midwifery education provider. The qualitative themes provide insight into the perspectives of those students who agreed to participate in the study. We were not able to explore the views of students who chose to not complete the questionnaire nor participate in the focus groups. Additionally, as with any questionnaire or focus group, there is the possibility of response bias in that students with stronger opinions were more likely to respond or voice their views. However, within the sample achieved, a range of views was represented.

\section{CONCLUSION}

Little is known about the effectiveness and sustainability of satellite-based, blended delivery programmes for the education of health practitioners.

A concern for us in designing this new curriculum was how we would ensure that the fundamental values of face-to-face dialogue and connection within midwifery practice were still retained. This had been a strong focus of our previous curriculum and, reassuringly, the findings have confirmed that these aspects have been retained in the new curriculum. The small group tutorials provide a regular ongoing place which enables this to happen.

This research on the midwifery tutorial model within a blended delivery programme demonstrates that the àkonga is valued by all students and seen as the "hub" of the programme. This model assists students to manage feelings of isolation and the complex demands of the programme alongside their personal lives. It has also enabled them to capitalise on being a student midwife in their own areas by building relationships and becoming part of a local community of practice of students, educators and practitioners. The àkonga as a community of inquiry is pivotal in enabling students to learn to bridge the gap between theory and practice.

\section{ACKNOWLEDGEMENTS AND CONFLICT OF INTEREST STATEMENT}

We would like to thank all the midwifery students who participated in this study and provided their views of the blended programme. The authors state that there are no conflicts of interest.

\section{REFERENCES}

Ashwin, P. (2005). Variation in students' experiences of the 'Oxford Tutorial'. Higher Education, 50, 631-644. Retrieved from ProQuest Central database.

Baum, F., MacDougall, C., \& Smith, D. (2006). Participatory action research. Journal of Epidemiology \& Community Health, 60(10), 854-857. http://dx.doi.org/10.1136/jech.2004.028662

Booth, A. (1996). Assessing group work. In A. Booth \& P. Hyland (Eds.), History in higher education (pp.276-297). Oxford, England: Blackwell.

Eggermont, S., Bloemendaal, P. M., \& van Baalen, J. M. (2013). E-learning any time any place anywhere on mobile devices. Perspectives on Medical Education, 2(2), 95-98. http://dx.doi.org/10.1007/s40037013-0045-4

Exley, K., \& Dennick, R. (2004). Small group teaching: tutorials, seminars and beyond. Abingdon, England: Routledge.

Garrison, D. R., \& Kanuka, H. (2004). Blended learning: Uncovering its transformative potential in higher education. Internet and Higher Education, 7, 95-105.

Glogowska, M., Young, P., Lockyer, L., \& Moule, P. (2011). How 'blended' is blended learning? Students' perceptions of issues around the integration of online and face-to-face learning in a continuing professional development (CPD) health care context. Nurse Education Today, 31, 887-891.

Güzer, B., \& Caner, H. (2014). The past, present and future of blended learning: an in depth analysis of literature. Procedia-Social and Behavioral Sciences, 116, 4596-4603.

Hendry, C. (2009). Report on Mapping the Rural Midwifery Workforce in New Zealand for 2008. New Zealand College of Midwives Journal, 41, 12-19. 
Kaur, M. (2013). Blended learning - its challenges and future. Procedia Social and Behavioral Sciences, 93, 612-617.

Kindon, S., Pain, R., \& Kesby, M. (2007). Participatory action research approaches and methods: connecting people, participation and place. London, England: Routledge.

King, A. (1993). From Sage on the Stage to Guide on the Side. College Teaching, 41(1), 30-35.

Koch, T., \& Kralik, D. (2009). Participatory action research in healthcare. Oxford, England: Blackwell Publishing Ltd.

Littlejohn, A., \& Pegler, C. (2007). Preparing for blended e-learning. Abingdon, England: Routledge.

Midwifery Council of New Zealand. (2007). Standards for approval of pre-registration midwifery education programmes and accreditation of tertiary education organisations. Wellington, New Zealand: Author.

Mills, D., \& Alexander, P. (2013). Small group teaching: a toolkit for learning. Retrieved from the Higher Education Academy website: https:// www.heacademy.ac.uk/system/files/resources/small_group_teaching_1.pdf Milne, T., Skinner, J., \& Baird, K. (2014). Survey results of first and second year New Zealand midwifery students' level of engagement in a flexible delivery programme. New Zealand College of Midwives Journal, 50, 5-10.

Palfreyman, D. (Ed.). (2008). The Oxford Tutorial: 'Thanks, you taught me how to think'. Retrieved from Oxford Centre for Higher Education Policy Studies website: http://oxcheps.new.ox.ac.uk/Publications/ Resources/OxCHEPS_OP1_08.pdf

Patterson, J., Baddock, S., Pairman, S., Griffiths, C., \& Miller, S. (2015). Evaluation of the learning components of a blended Bachelor of Midwifery programme: student perceptions of how these contributed to their learning and their readiness for practice. New Zealand College of Midwives Journal, 51, 50-58.

Reason, P., \& Bradbury, H. (2006). Handbook of action research. London, England: Sage.

Schneider, B. (2010) Hearing (our) voices; Participatory research in mental health. Toronto, Canada: University of Toronto Press.

Sidebotham, M., Jomeen, J., \& Gamble, J. (2014). Teaching evidence based practice and research through blended learning to undergraduate midwifery students from a practice based perspective, Nurse Education in Practice, 14, 220-224.

Siemens, G. (2008). Learning and knowing in networks: Changing roles for educators and designers. Presented to ITFORUM for discussion. Retrieved from Inge de Waard website: http://www.ingedewaard.net/ papers/connectivism/2008_siemens_Learning_Knowing_in_Networks_ changingRolesForEducatorsAndDesigners.pdf

Skrypnyk, O., Joksimovic, S., Kovanovic, V., Dawson, S., Gasevic, D., \& Siemens, G. (2015). The history and state of blended learning. In G. Siemens, D. Gasevic, \& S. Dawson, (Eds.). Preparing for the digital university: a review of the history and current status of distance, blended, and online learning. Retrieved from University of Texas Arlington website: http://linkresearchlab.org/PreparingDigitalUniversity.pdf

Thorne, S., Reimer Kirkham, S., \& O’Flynn- Magee, K. (2004). The analytic challenge in interpretive description. International Journal of Qualitative Methods, 3(1), 1-21.

Trigwell, K., \& Ashwin, P. (2003). Undergraduate students' experience of learning at the University of Oxford. Oxford, England: Institute for the Advancement of University Learning. Retrieved from The University of Sydney website: https://sydney.edu.au/education-portfolio/ei/aboutus/ olcpfinal.pdf

Wenger-Trayner, E., \& Wenger-Trayner, B. (2015). Introduction to communities of practice: A brief overview of the concept and its uses. Retrieved from http://wenger-trayner.com/introduction-to-communitiesof-practicel

Wilson, J. (2008). Bridging the theory practice gap. Australian Nursing Journal, 16(4), 25.

\section{Accepted for publication July 2017}

Kensington, M., Davies, L., Daellenbach, R., Deery, R., \& Richards, J. (2017). Using small tutorial groups within a blended Bachelor of Midwifery programme: Bridging the theory-practice divide. New Zealand College of Midwives Journal, 53, 38-44.

http://dx.doi.org/10.12784/nzcomjn153.2017.5.38-44 